\title{
Variability of morphophysiological parameters of Chenopodium album and Taraxacum officinale in the conditions of Kazan
}

\author{
Natalya S. Arkhipova*, Kadriy K. Ibragimova, and Alisa R. Ilyasova \\ Kazan (Volga Region) Federal University, Kazan, Russia
}

\begin{abstract}
One of the promising methods for the integral assessment of the quality of the environment and the vital activity of herbaceous plants is the assessment of the state of living organisms by the morphometric characters development stability. The study revealed an increase in the variability of morphological characters in the plants of lamb's quarters (Chenopodium album) and milk-witch gowan (Taraxacum officinalis) in areas with a high level of technogenic pollution. Phenotypes with smaller sizes of vegetative organs prevailed there, as compared with the area with a low level of pollution. At the same time, viable seeds and seedlings were formed in the plants of urban cenoses.
\end{abstract}

\section{Introduction}

Urbanization affects the plants of urban ecosystems as a stress factor, which manifests itself in changes in individual functions and parameters of plants. Urban flora is characterized by pronounced variability of morphostructural characters, which is a survival mechanism in the unstable natural environment of cities [1,2]. The use of various ecological and physiological indicators of the state of plants is promising in the system of the urban environment phytomonitoring $[1,2,3]$. It is considered, that plants are reliable indicators of environmental pollution by various toxic substances. They are forced to adapt to stressors with the help of physiological and morphological reconstructions of the organism, sinse they are not able to move. Fixation and evaluation of these changes provide a reliable picture of the conditions of the place of growth of plants and reflect the state of the urban environment [4].

The aim of the work was to study the influence of urban traffic pollution on the morphophysiological characteristics of lamb's quarters and milk-witch gowan as the most common types of urban flora.

\section{Materials and methods}

The collection of material was carried out in June-July 2019. The study plots were ranked according to the degree of traffic load and the level of pollution [5]: control - $120 \mathrm{~km}$ from

${ }^{*}$ Corresponding author: NSArhipova@kpfu.ru 
Kazan (traffic intensity $108 \pm 19$ cars/hour), average - in the central part of the city, where the passage of freight transport is prohibited (2296 \pm 118 cars/hour), high - in the industrial area of Kazan with heavy traffic $(4564 \pm 120$ cars/hour).

In total, 9 areas $\left(100 \mathrm{~m}^{2}\right)$ were laid out, on each of them a cenopopulation (CP) of the studied plant species was identified, where 10 young reproductive (g1) specimens of lamb's quarters (Chenopodium album L.) and milk-witch gowan (Taraxacum officinale Wigg.) were withdrawn during the period of mass flowering. The pollution effect on plants was assessed by changes in morphometric indicators (Tables 1 and 2). The viability of seeds and seedlings was assessed by laboratory germination and root length, respectively. The seeds of the studied plants were germinated in water culture on solutions of $\mathrm{Cd}\left(\mathrm{NO}_{3}\right)_{2} \times 4 \mathrm{H}_{2} \mathrm{O}$ and $\mathrm{ZnSO}_{4} \times 7 \mathrm{H}_{2} \mathrm{O}$ salts at concentrations of $10 \mu \mathrm{M} / \mathrm{L}$ and $1 \mathrm{mM} / \mathrm{L}$ (doses within the range of HM concentrations actually existing under natural conditions) [6].

The level of interpopulation and intrapopulation variability of traits was estimated by the value $\left(C_{V}, \%\right)$, the index of phytocenotic plasticity $\left(I_{p}\right)$, the index of vitality of cenopopulations (IVC) was calculated as the sum of the ratios of the average value of the CP's i-th feature to the average value of all CPs' i-th feature, divided by $N$ - the number of features [2]; comparison of mean values of samples by one-way analysis of variance (ANOVA) was performed, where the significance of differences was taken at $p<0.05$.

\section{Results and Discussion}

Analysis of quantitative and metric indicators of vegetative and generative organs of $C$. album and T. officinale (Table 1 and 2) showed that in the CP with a high level of technogenic load many of these indicators were significantly lower than in the control area. The minimum trait values are typical for milk-witch gowan and lamb's quarters specimens from the area with a high level of pollution.

Table 1. Morphometric indicators of Chenopodium album depending on the level of pollution

\begin{tabular}{|c|c|c|c|c|c|c|}
\hline \multirow[t]{4}{*}{ Trait } & \multicolumn{6}{|c|}{ Pollution level } \\
\hline & \multirow{2}{*}{\multicolumn{2}{|c|}{$\begin{array}{c}\text { Control } \\
I V C=1.26\end{array}$}} & \multirow{2}{*}{\multicolumn{2}{|c|}{$\begin{array}{c}\text { Average } \\
I V C=1.02\end{array}$}} & \multirow{2}{*}{\multicolumn{2}{|c|}{$\begin{array}{c}\text { High } \\
I V C=0.77\end{array}$}} \\
\hline & & & & & & \\
\hline & $\mathbf{M} \pm \mathbf{m}$ & $\begin{array}{l}C_{v}, \\
\%\end{array}$ & $\mathbf{M} \pm \mathbf{m}$ & $\begin{array}{l}\mathrm{C}_{\mathrm{V}}, \\
\%\end{array}$ & $\mathbf{M} \pm \mathbf{m}$ & $\begin{array}{l}\mathrm{C}_{\mathrm{v}} \\
, \%\end{array}$ \\
\hline Height, $\mathrm{cm}$ & $20.95 \pm 0.87$ & 23 & $17.70 \pm 1.25^{* *}$ & 38 & $8.24 \pm 0.52^{*}$ & 34 \\
\hline $\begin{array}{l}\text { Number of } \\
\text { leaves, pcs }\end{array}$ & $13.27 \pm 0.51$ & 21 & $14.14 \pm 0.59^{* *}$ & 22 & $11.21 \pm 0.40^{*}$ & 19 \\
\hline Leaf length, $\mathrm{cm}$ & $4.48 \pm 0.14$ & 18 & $3.21 \pm 0.15^{*}$ & 25 & $2.91 \pm 0.12^{*}$ & 21 \\
\hline Leaf width, $\mathrm{cm}$ & $3.32 \pm 0.13$ & 21 & $2.46 \pm 0.13^{*}$ & 28 & $2.31 \pm 0.10^{*}$ & 22 \\
\hline $\begin{array}{l}\text { Number of side } \\
\text { shoots, pcs }\end{array}$ & $11.00 \pm 0.57$ & 28 & $12.82 \pm 0.72^{* *}$ & 29 & $8.68 \pm 0.5^{*}$ & 31 \\
\hline $\begin{array}{l}\text { Weight of } 1000 \\
\text { seeds, mg }\end{array}$ & $853 \pm 6.5$ & - & $399 \pm 8.6$ & - & $240 \pm 18.5$ & - \\
\hline
\end{tabular}

To characterize the vitality of cenopopulations as a whole, we calculated the index of vitality of cenopopulations (IVC) based on the size spectra of individuals of the generative age state. It was revealed (Tables 1 and 2) that the vital state of cenopopulations, assessed by us according to the vitality index (IVC), was lower in urban CP than in the control CP. Consequently, the "Control" area corresponds to the best conditions for growth potential realization. 
Assessment of the variability of morphological parameters at the interpopulation level showed that a high level of variability $\left(C_{V}>30 \%\right)$ in $C$. album had the plant height trait, and in T. officinale - all traits (except for the head diameter). Under conditions of an increased technogenic load (all urban CPs), the $C_{V}$ of the studied parameters in the lamb's quarters was higher than in the control; in milk-witch gowan a high level of pollution caused an increase in the variability of the length, width and number of leaves, as well as the height of the flower stalk.

Table 2. Morphometric indicators of Taraxacum officinale depending on the level of pollution

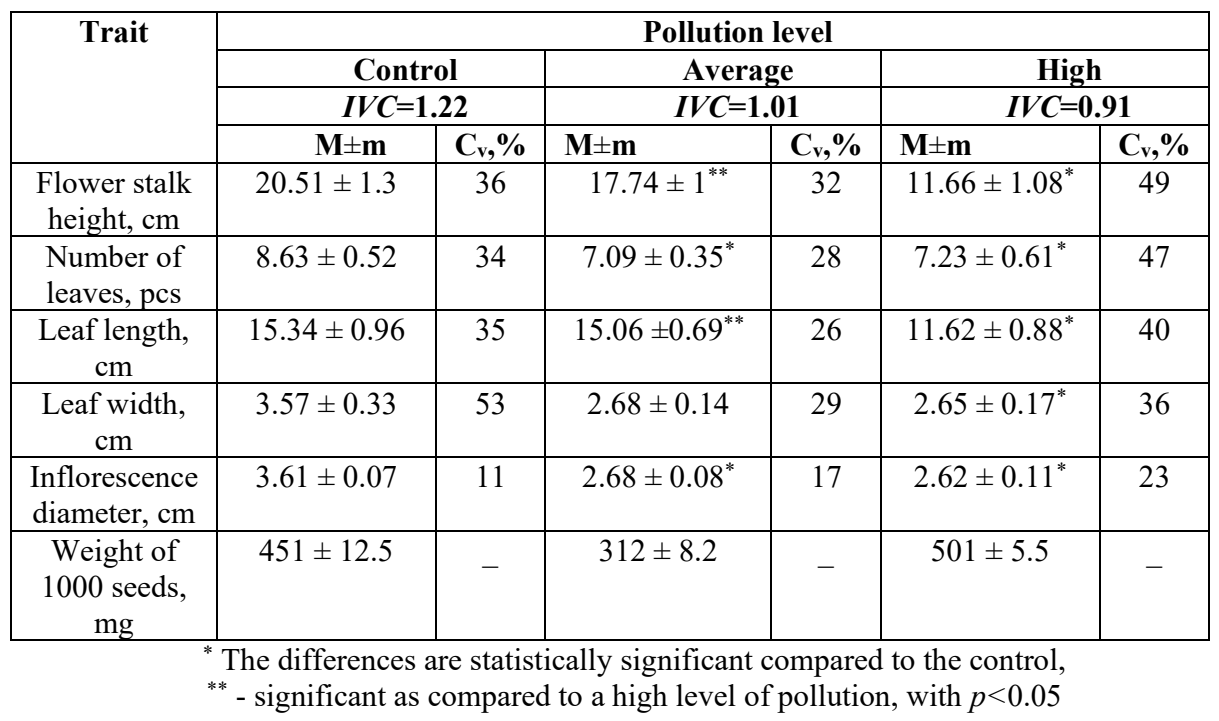

Plasticity, in contrast to variability, is an independent phenomenon, consisting in the change in the average value of the morphometric parameters of plants along certain gradients. Plasticity is of great adaptive importance in plant life [7], it is the main mechanism of plant adaptability to changing conditions.

The analysis of phytocenotic plasticity indices $\left(I_{p}\right)$ shows that $C$. album is most responsive to changes in habitat conditions, such as plant height $\left(I_{p}=0.61\right)$, and $T$. officinale has the height of the flower and the length of the sheet plate (0.69 and 0.62). The least plastic in both species was the number of leaves $(0.27$ and 0.31$)$. Usually plasticity is manifested in reversible changes in the structures and functions of the body when exposed to new habitat conditions and ensures the preservation of the vitality of individuals, their adaptation to adverse environmental factors [3]. Thus, habitat conditions significantly affect both the quantitative and linear morphological characteristics of plants of the species under study.

One of the leading factors ensuring the successful growth of plants in urban conditions is the ability to produce viable seeds $[8,9]$. The study showed that with an average and high level of pollution in C. album the weight of 1000 seeds decreased by 2.1 and 3.6 times. For T. officinale, on the contrary, at a high level of pollution an increase in this parameter by $10 \%$ was noted in comparison with the control. At the same time, in plants of urban cenoses with a high and very high level of technogenic load, such indicators as the germination energy and root length decreased in C. album (by 35 and 53\%, respectively), and practically did not change in $T$. officinale relative to the parameters of the control plot.

Long-term exposure to pollutants of plants can cause not only toxic effects, but also adaptive responses $[8,10]$. In this regard, it was of interest to reveal the metal resistance of seeds of the studied species, depending on the growing conditions of the mother plants. 
The effect of the influence of $\mathrm{Cd}\left(\mathrm{NO}_{3}\right)_{2}$ and $\mathrm{ZnSO}_{4}$ solutions on the root length of Chenopodium album and Taraxacum officinale of different CP was assessed by Wilkinson's Tolerance Index $\left(\mathrm{I}_{\mathrm{T}}\right)$ as the ratio of the value of the measured indicator in HM solution to the value of this indicator in water (Table 3 ).

Table 3. Tolerance Indexes (IT) of the root length of Chenopodium album and Taraxacum officinale, depending on the level of pollution in exposure to HM salt solutions

\begin{tabular}{|c|c|c|c|}
\hline \multirow{2}{*}{ Variant } & \multicolumn{3}{|c|}{ Pollution level } \\
\cline { 2 - 4 } & Control & Average & High \\
\cline { 2 - 4 } & \multicolumn{3}{|c|}{ Chenopodium album } \\
\hline $\mathrm{Cd}$ & $\mathbf{0 . 2 7}$ & $\mathbf{0 . 2 9}$ & $\mathbf{0 . 2 2}$ \\
\hline $\mathrm{Zn}$ & $\mathbf{0 . 5 8}$ & $\mathbf{0 . 6 1}$ & $\mathbf{0 . 7 6}$ \\
\hline \multicolumn{4}{|c|}{ Taraxacum officinale } \\
\hline $\mathrm{Cd}$ & $\mathbf{0 . 7 2}$ & $\mathbf{0 . 8 9}$ & $\mathbf{0 . 6 1}$ \\
\hline $\mathrm{Zn}$ & $\mathbf{0 . 6 5}$ & $\mathbf{1 . 2 5}$ & $\mathbf{0 . 8 5}$ \\
\hline
\end{tabular}

The data in the table show that in C. album HM inhibited root growth, cadmium was especially toxic, and its negative effect was noted both for seeds from the Control area and from areas with pollution. We have shown that at a high and medium level of pollution of T. officinale place of growth, the $\mathrm{I}_{\mathrm{T}}$ indicators of the root length were higher than in the Control variant. The literature tells that a response to regular technogenic pollution can be an increase in plant resistance to the effects of certain pollutants, including HMs [10].

\section{Conclusions}

Thus, in the conditions of the city of Kazan in areas with a high level of technogenic pollution, we noted an increase in the variability of morphological characters in C. album and $T$. officinale plants and a predominance of phenotypes with smaller sizes of vegetative organs than in plants from the control area.

It is known from the literature that an increase in the variability of traits often occurs under the influence of stress factors and can be the basis for the formation of more stable morphological types of plants.

Solutions of HM salts inhibited physiological processes: seed germination and root growth. It was not possible to reveal the dependence of the metal resistance of C. album seeds on the place of their collection. A negative effect of HM was observed both for seeds from urban CPs and from the control area CPs. At the same time, T. officinale seeds, formed under conditions of medium and high levels of pollution, were characterized by greater resistance to $\mathrm{HM}$ as compared to the control. The root length on the $\mathrm{ZnSO}_{4}$ solution was greater than when the seeds were germinated on water $\left(\mathrm{I}_{\mathrm{T}}>1\right)$. Earlier [11], we have shown for $T$. officinale an increase in comparison with the control of the mass and energy of seed germination, the activity of enzymes at an increased anthropogenic load (2100 cars per hour), which was considered as activation of the plant's defence systems. With a further increase in the intensity of traffic, all physiological indicators were lower than in the control. It is discussed in the literature that such effects are adaptive, such as the phenomenon of overcompensation, in other words, the excessive activation of the plant's defence systems [12]. 


\section{References}

1. Yu. A. Zlobin, Population ecology of plants: current state, points of growth (Universitetskaya kniga, Saint-Petersburg, 2009)

2. A.R. Ishbirdin., M.M Ishmuratova, Methods of Population Biology: materials of the VII All-Russian Population Workshop. Syktyvkar, 2, 113-120 (2004)

3. A.S. Kashin, N.A. Petrova, I.V. Shilova, Saratov University Proceedings. Series: Chemistry. Biology. Ecology, 17, 103-110 (2017)

4. L.V. Pestova, O.V. Ryazantseva, PolzunovskyVestnik, 4, 99-112 (2004)

5. GOST 32965-2014. Public roads. Traffic flow intensity accounting methods (Standartinform, Moscow, 2016

6. T.V. Guykova, Bezel V.S., Pozolotina V.N., Severukhin O.A. Ecology, 2, 432-437 (2002)

7. E.L. Kordum, Ukr. Bot. magazine, 58 (2), 141-152 (2001)

8. M.P. Solntseva, K.L. Glazunova, J. of G. Biology, 71, 163-175 (2010)

9. T.A. Konchina, M.V. Guseva, Molodoy Uchenyy (Young Scientist), 23.2. 118-122 (2015)

10. D.I. Bashmakov, A.S. Lukatkin, Ecological-physiological aspects of the accumulation and distribution of heavy metals in higher plants (Mordov. Un-t, Saransk, 2009)

11. D. S. Elagina, V.V. Nikolenko, S.F. Kotov, V.N. Vorobyev, N.S. Arkhipova, Indo Am. J. P. Sci, 05(04), 2326-2334 (2018)

12. L.Kh. Eidus, Biophysics, 50.4, 607-617 (2005) 